\title{
НОВЫЕ НАХОДКИ ПЛАТИСОЛЕНИТИД И ГАСТРОПОД ИЗ ЛОНТОВАСКОГО ГОРИЗОНТА ЭСТОНИИ
}

При изучении отложений балтийской серии на территории Эстонии нами собран новый материал по платисоленитидам и гастроподам. Изучение этого материала позволило выделить новый вид платисоленитид, определить систематическое положение уже известного вида гастропод и выяснить вертикальное и горизонтальное распространение указанных фоссилий.

Автор признателен А. Ю. Розанову, обратившему ее внимание на сходство лонтоваской гастроподы с видами рода Aldanella, a также К. Менс и В. В. Миссаржевскому за ценные советы.

Описанный материал хранится в Институте геологии АН ЭССР в Таллине.

\section{Платисоленитиды}

Трубки платисоленитид широко распространены в балтийской серии (дотрилобитовые слон) на Восточно-Европейской платформе. Наиболее характерны они для лонтоваского горизонта; в ровенском горизонте они встречаются реже, а в нижних слоях его отсутствуют совсем (Кирьянов, 1968). Единичные экземпляры платисоленитид установлены и в вышележащих отложениях раннего кембрия (Лиелдиена, Фридрихсоне, 1968). В изученной коллекции наряду с прямыми трубками Platysolenites antiquissimus Eichw. и P. lontova Öpik нами обнаружены и плоскоспирально завернутые формы, описываемые ниже как новый вид P. spiralis. Распределены названные виды платисоленитид по разрезу и латерали неодинаково (рис. 1-2). P. antiquissimus встречается по всему разрезу лонтоваского горизонта, причем в низах разреза в песчаных отложениях весьма редко. $P$. lontova приурочен к средней части горизонта, сложенной преимущественно алевритовыми и алевритистыми глинами. $P$. spiralis встречается лишь в верхах горизонта, в толще чередующихся глин и алевролитов. Верхняя часть разреза сохранилась от последующей денудации только в северо-западной части Эстонии (Менс, Пиррус, 1977).

Спиральная форма платисоленитид из нижнего кембрия Северной Норвегии впервые обнаружена и описана Г. Хамаром, который отнес ее, наряду с прямой формой, к виду $P$. antiquissimus (Hamar, 1967). Однако спиральная морфология нашей формы и ее приуроченность к определенному стратиграфическому интервалу дают нам основание рассматривать ее как самостоятельный вид под названием $P$. spiralis. 


\section{Род Platysolenites Pander, 1851}

\section{Platysolenites spiralis sp. nov.}

Таблица, фиг. 2-4

1967. Platysolenites antiquissimus - Hamar, c. 90, табл. I, фиг. 4, табл. II, фиг. 1.

Гол от ип. Экз. № Va 715 , табл., фиг. 3, нижний кембрий, балтийская серия, лонтоваский горизонт, скв. Аре, гл. 401,2 м.

О пи с ани е. При предположительно полной сохранности - это маленькие кремневые плоскоспиральные трубки, открытые с обеих сторон. Обычно они встречаются в виде слабо изогнутых фрагментов. Внешняя поверхность трубок сегментирована, сегментация нерегулярная и выражена не всегда ясно. Размеры, мм: поперечное сечение свернутой формы $1,2-1,3$; диаметр трубки $0,27-0,6$; толщина трубки $0,025-0,07$; длина сегментов $0,03-0,3$.

С равнен н е. От других видов рода $P$. spiralis отличается спиральносвернутой формой, несколько меньшим диаметром трубки (у P. antiquissimus достигает 3 мм - табл., фиг. 5) и отсутствием на трубке утолщений, характерных для $P$. lontova (табл., фиг. 1).

Геологический возраст и распространение. ЭССР, ниж-

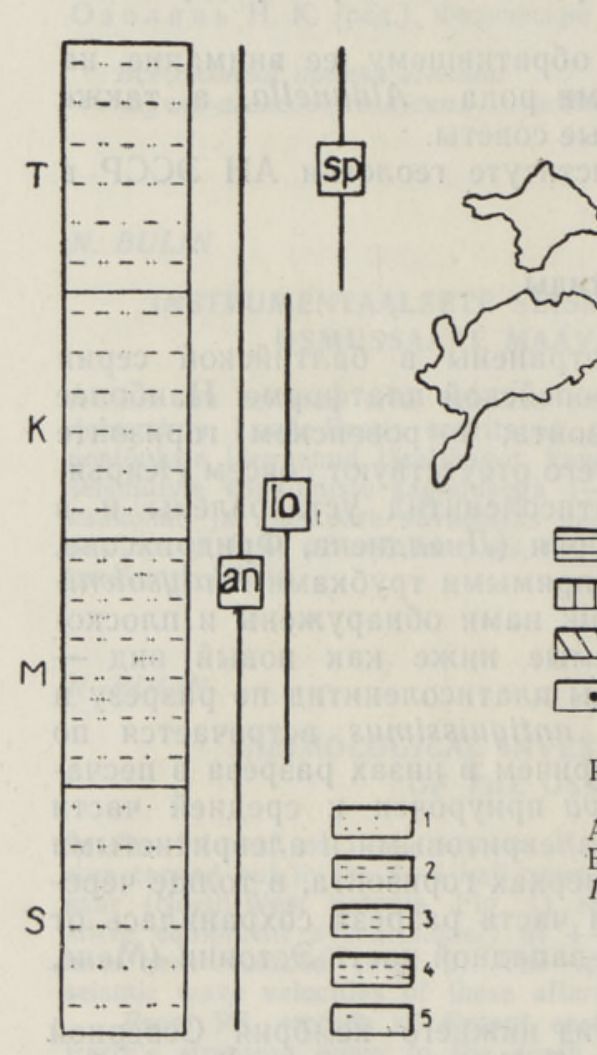

Рис. 2. Распространение платисоленитид и места находок гастропод в Эстонин.

A - Platysolenites antiquissimus, Б - P. lontova,

В - P. spiralis, $\Gamma-$ находки Aldanella kunda:

1 - Хаапсалу, 2 - Хирвли, 3 - Вахасту, 4 Ваки, 5 - Кунда, 6 - Лехтсе, 7 - Рясна.

Рис. 1. Распространение Platysolenites antiquissimus (an), Platysolenites lontova (lo) и Platysolenites spiralis (sp) в лонтоваском горизонте.

$S$ - сямнская (базальная) пачка, $M$ - махуская пачка, $K-$ кестлаская пачка, $T$ - таммнеямиская пачка. 1 - песчаник, 2 - пелитовый алевролит, 3 - алевритовая глина, 4 - алевритистая глина, 5 - прослои алевритов. 

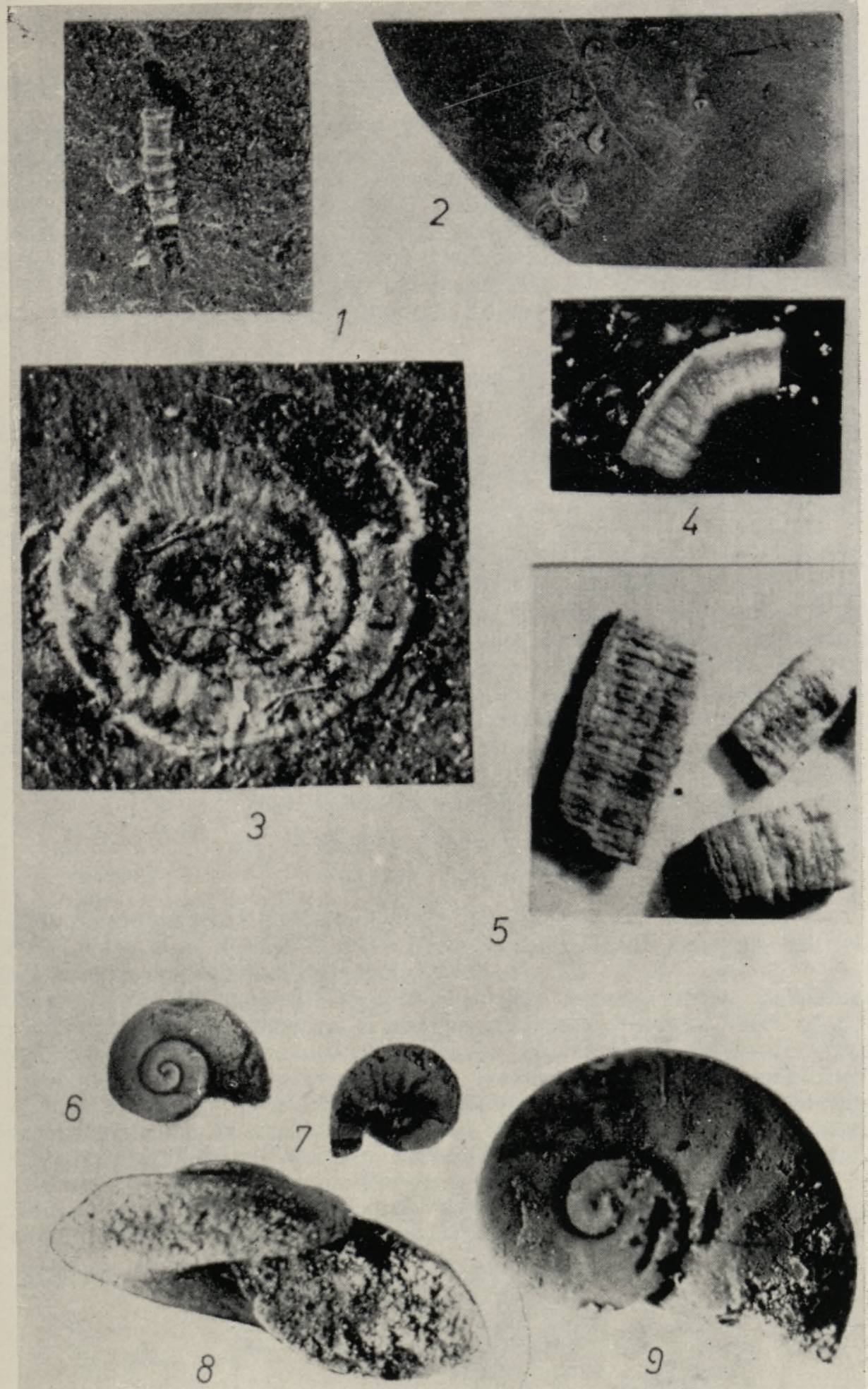

Platysolenites lontova Opik. Фиг. 1. Vа 718 , обн. Кунда, $× 5$. Platyso!enites spiralis sp. nov. Фиг. 2. Va 716, скв. Коловере-12, гл. 255,2 м ×2,5. Фиг. 3. Vа 715 , голотип, скв. Aре, гл. 401,2 м, Х27. Фиг. 4. Vа 717, изогнутый фрагмент, скв. Коловере-12, гл. $259,5 \mathrm{M}, \times 28$.

Platysolenites antiquissimus Eichwald. Фиг. 5. Vа 719, скв. Валгу-303, гл. 298,0 м, $\times 9$. Aldanella kunda (Opik). Фиг. 6, 8. Ga 039, 6 $-\times 8,8-\times 20$. Фиг. 7. Ga 040, $\times 10$. Фиг. 9. Ga $041, \times 19$. Все гастроподы из обн. Кунда. 

ний кембрий, балтийская серия, лонтоваский горизонт; Норвегия, нижний кембрий, брейвикская свита.

М а тери ал. Около 100 экз. хорошей сохранности: скв. Ригулди (гл. 159,2 м), скв. Паливере (гл. 228,5-229,6 м), скв. Виртсу (гл. 352,0355,0 м), скв. Коловере-12 (гл. 255,2-259,5 м), скв. Селисте (гл. 529,0531,0 м), скв. Каллавере (гл. 40,0-42,5 м), скв. Ласила (гл. 197,5 м), скв. Вахасту-17 (гл. 265,0 м), скв. Валгу-303 (гл. 290,5-297,5 м), скв. Ape (гл. 401,2 м), обн. Копли, Виймси, Колгакюла.

\section{Гастроподы}

Один экземпляр гастроподы обнаружен А. Эпиком и описан под названием Pleurotomaria? kunda (Öpik, 1926). Собранный нами из нескольких разрезов материал содержит около 30 экземпляров. Все находки приурочены к наиболее глинистой части верхней половины лонтоваского горизонта (кестлаская пачка; Pirrus, 1973).

Представители мезо-кайнозойского рода Pleurotomaria Sowerby имеют ширококоническую или трубкообразную раковину с косо овальным или округленно ромбическим устьем (Пчелинцев, 1960, с. 71 ). В отличие от них раковины наших гастропод из лонтоваского горизонта характеризуются дискоидальной формой и овальным устьем. По этим признакам рассматриваемая форма сходна с представителями широко распространенного в раннем кембрии Сибирской платформы рода Aldanella Vostokova (Востокова, 1962).

\section{Род Aldanella Vostokova, 1962 Aldanella kunda (Öpik)}

Таблица, фиг. 6-9

1926. Pleurotomaria ? kunda - Öpik, c. 45-46, фиг. 2.

Го л о ти п. Экз. № Ga 17, колл. 51 А. Эпика, нижний кембрий, балтийская серия, лонтоваский горизонт, Кунда.

О пи с ание. Маленькие с низким завитком дискоидальные раковины в $1,5-2,5$ оборота. Обороты в сечении овальные. Верхняя часть оборотов слабо выпуклая, нижняя уплощенная. Пупок воронковидный. Устье овальное и находится наклонно к оси раковины. Антиспиральный синус хорошо выдержан на верхней поверхности оборотов. Линии нарастания непосредственно от шва загнуты назад под углом $30-45^{\circ}$, а на нижней поверхности оборотов выгнуты вперед. Иногда видны складки, параллельные линиям нарастания. Размеры раковин даны на рис. 3 .

Изменчи вость. Наблюдаются колебания в размерах раковин и в числе оборотов. Линии нарастания видны не у всех экземпляров. Бимо-

0

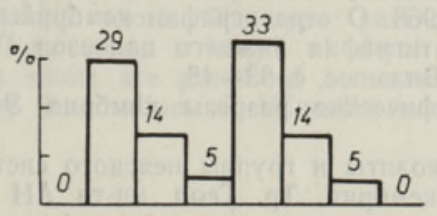

$\begin{array}{llllllll}0.1 & 0,3 & 0,5 & 0.7 & 0,9 & 1,1 & 1,3 & 1,9>1,9\end{array}$ $\delta$

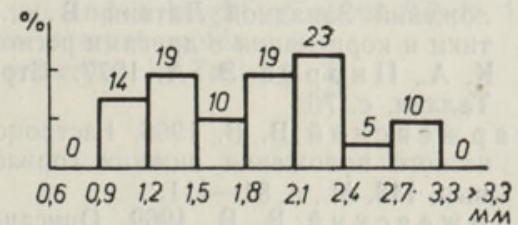

Рис. 3. Высота (а) и ширина (б) раковины Aldanella kunda (Ӧik). 


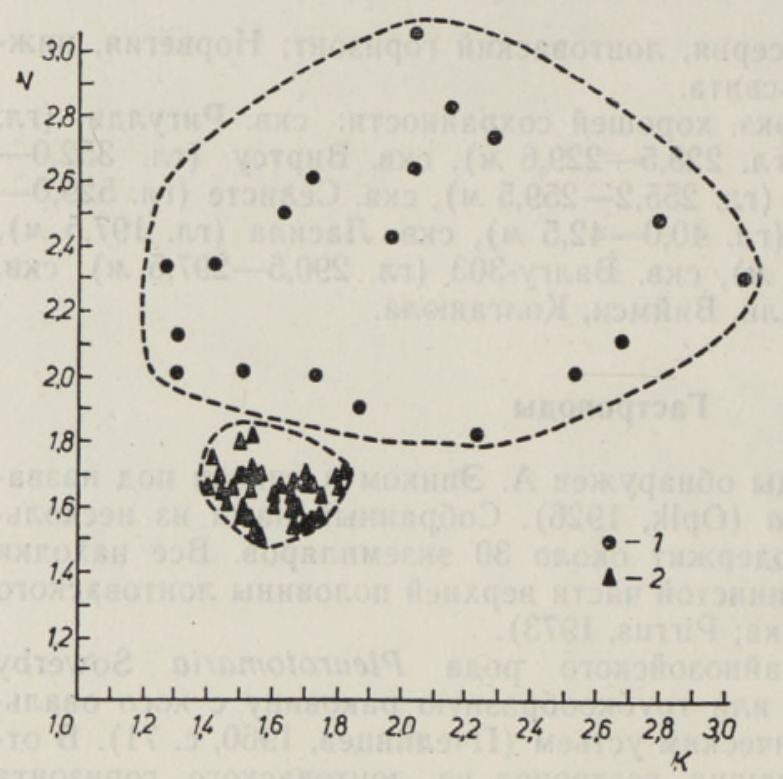

Рис. 4. Соотношение размеров раковины и устья. 1 - Aldanella kunda, 2 - Aldanella rozanovi.

$N$ - отношение длины к высоте раковины; $K$ - отношение длины к ширине устья.

дальное распределение высоты и ширины раковины указывает на неоднородность изученного материала. Не исключено, что он содержит представителей более одного таксона.

С р а в н ен и е. Описанный вид близок к Aldanella rozanovi Miss. (Миссаржевский, 1966,1969$)$, отличается от него размерами, другим отношением длины к высоте раковины (рис. 4), а также бо́льшей шириной последнего оборота. Типовой вид рода A. attleborensis (Shaler et Foerste) отличается от $A$. kunda (Öpik) ясно выраженной килеватостью, от A. operosa Miss. - широким пупком и килеватостью оборотов, от A. crassa Miss. - несколько уплощенной верхней стороной и формой сечения оборотов, от $\dot{A}$. utchurica Miss. - более высоким завитком.

Ге ологический воз раст и распространение. ЭССР, нижний кембрий, балтийская серия, лонтоваский горизонт.

М а т е р и а л. 28 экземпляров, в основном пиритовые ядра. Обн. Кунда, скв. Хаапсалу-3 (гл. 248,1 м), скв. Хирвли (гл. 90,0 м), скв. Лехтсесоо (гл. 174,0 м), скв. Рясна (гл. 195,0-197,0 м), скв. Вахасту (гл. 277,6286,0 м), скв. Ваки (гл. 348,5 м).

\section{ЛИТЕ Р А Т Р А}

В остоко в а В. А. 1962. Кембрийские гастроподы Сибирской платформы и Таймыра. Сб. статей по палеонтологии и биостратиграфии, вып, 28 , НИИГА. Л., с. $51-72$.

К и р я но в тийской серии Волыно-Подолин. В кн.: Палеонтология и стратиграфия нижнего палеозоя Волыно-Подолии. Кнев, с. $5-26$.

Лиелдиена Э. К., Фридрихсоне А. И. 1968. О стратиграфии кембрийских отложений Западной Латвии. В кн.: Стратиграфия нижнего палеозоя Прибалтики и корреляция с другими регионами. Вильнюс, с. $33-48$.

Менс К. А., Пир рус Э. А. 1977. Стратиграфические разрезы кембрия Эстонии. Таллин, с. 76 .

М исс а р же в ски й В. В, 1966. Гастроподы, хиолиты и группы неясного систематического положения нижних горизонтов кембрия. Тр. Геол. ин-та АН СССР, вып. 148. М., с. $81-111$.

М и сс ар же в ски й В. В. 1969. Описание хиолитов, гастропод, хиолительминтов, каменид и форм неясного систематического положения. Тр. Геол. ин-та АН СССР, вып. 206. М., с. 105-175. 
П челинце в В. Ф. 1960. Pleurotomaria Sowerby. В кн.: Основы палеонтологии. Моллюски. Брюхоногие. М., с. 71.

Eichwald, E. 1860. Lethaea Rossica ou Paléontologie de la Russie. Stuttgart, p. 1657.

$\mathrm{H}$ a mar, G. 1967. Platysolenites antiquissimus Eichw. (Wermes) from the Lower Cambrian of northern Norway, NGU, No. 249, 22, 87-95.

Pirrus, E. 1973. Mida teame sinisavist. Eesti Loodus, Nr. 11, 646-653.

Ö p i k, A. 1926. Ober den estländischen blauen Ton. Tartu Ulikooli Geol. Inst. Toimet., nr. $33(1), 39-47$.

Институт геологии

Академии наук Эстонской ССР
Поступнла в редакцию

18/IV 1977

\section{Erika POSTI}

\section{UUSI ALAMKAMBRIUMI PLATUSOLENITIIDI JA GASTROPOODI LEIDE EESTI LONTOVA LADEMES}

Artiklis on kirjeldatud perekonna Platysolenites unt liiki $P$. spiralis, mida on leitud lontova lademest. Joonistel 1 ja 2 on esitatud Platysolenites antiquissimus'e, P. lontova ja $P$. spiralis'e vertikaalne ja horisontaalne levik. On esitatud ka Aldanella kunda uutel leidudel põhinev täpsustatud kirjeldus.

\section{Erika POSTI}

\section{NEW FINDS OF PLATYSOLENITIDS AND GASTROPODS FROM THE LONTOVA STAGE OF ESTONIA}

The present article contains a description of Early Cambrian gastropods and a new species, Platysolenites spiralis, from the Lontova Stage. The distribution of $P$. antiquissimus, $P$. lontova and $P$. spiralis in Estonia and their vertical range in the Lontova Stage are presented in Text-figs 1, 2.

\section{Platysolenites spiralis sp. nov.}

Table, Figs 2-4

Holotype. Va 715, Lontova Stage, Are boring, depth 401,2 m, Pl., Fig. 3.

Description. Diminutive helical-shaped tubes, commonly broken into best pieces. Diameter of the tubes varies from 0.27 to $0.6 \mathrm{~mm}$, the distance between the annulations varies from 0.03 to 0.3 ; the wall thickness of the tubes varies from 0.025 to $0.07 \mathrm{~mm}$.

\section{Aldanella kunda (Opik).}

Table, Figs $6-9$

1926. Pleurotomaria ? kunda - Öpik, p. 45-46, Fig. 2.

$\mathrm{H}$ ol o t y pe. Ga 17, coll. 51, Opik, Lontova Stage, Kunda.

Description. Small shells coiled in a low dextral spiral with oval aperture. A shell has 1.5-2.5 whorls. The upper part of the whorl is smooth or sculptured with growth lines. They attain a length of about 0.9 to 3.3 and a height of about 0.3 to $1.9 \mathrm{~mm}$. Genera shells are preserved as small pyritic internal molds.

The distribution of Aldanella kunda is presented in Text-fig. 2. 